Recepción: 12/11/2014

Evaluación: 16/11/2014

Aprobación: 09/12/2014

Artículo de Investigación Científica

\title{
HISTORIA DE VIDA: LA MAESTRA FLOR DE OROZCO
}

\author{
Mónica Liset Valbuena Porras \\ Universidad Pedagógica y tecnológica de Colombia \\ Grupo HISULA \\ Línea de Investigación: Formación de Educadores \\ Mujer y Género \\ moniklisetv@hotmail.com
}

\begin{abstract}
RESUMEN
Esta investigación ${ }^{\mathbf{1}}$ busca analizar y comprender la labor de la maestra rural desde su entorno familiar, social y cultural, a través de la incidencia de las transformaciones socio-políticas que se gestaron a nivel nacional, regional y local durante el siglo XX.

Los enfoques desarrollados para este trabajo son el de la Historia social de la educación ${ }^{2}$ y el de la Educación comparada, para tener una visión teórica, ideológica, política-filosófica que permita aproximarse al objeto de estudio a través de la historia de vida, que contribuye a la construcción de la memoria individual y colectiva de los pueblos.
\end{abstract}

Palabras clave: Maestra rural, Historia de vida, condiciones socio-económicas, formación, desigualdad.

1. Diana Soto Arango y Justo Cuño Bonito (coords.). La maestra rural en Colombia y Guatemala. Siglos XX y XXI. Historias de vida e intervención educativa de la Universidad. Proyecto de investigación interinstitucional con la Universidad Pablo de Olavide de España y el Grupo de investigación Historia y Prospectiva de la Universidad Latinoamericana-HISULA.

2. María Isabel Corts Giner, Alejandro Ávila Fernández, María Consolación Calderón y Ana María Montero. Historia de la Educación. Cuestiones previas y perspectivas actuales. Sevilla: GIPES, 1996, p. 73. 


\title{
LIFE STORY: THE MASTER FLOR DE OROZCO
}

\begin{abstract}
This research seeks to analyze and understand the work of the rural teacher through her family, social and cultural environment, and through the impact of socio-political transformations that took place at national, regional, and local level during the twentieth century.

The approaches developed for this work include the social history of education and comparative education in order to gain a theoretical, ideological and political-philosophical vision to approach the object of study through the history of life, which contributes to the construction of individual and collective memory of peoples.
\end{abstract}

Key words: Rural teacher, history of life, socio-economic situation, education, inequality.

\section{HISTORIA DE VIDA: DA PROFESSORA FLOR DE}

OROZCO

\section{RESUMO}

Esta pesquisa tem como objetivo analisar e compreender o trabalho da professora rural a partir de seu ambiente familiar, social e cultural, através do impacto das transformações sócio-políticas que foram desenvolvidas a nível nacional, regional y local durante el século XX.

As abordagens desenvolvidas para este trabalho são a da historia social da educação e da educação comparativa, para ter uma visão teórica, ideológica, política-filosófica que permite se aproximar do objeto de estudo através da historia de vida, que contribui à construção da memoria individual e colectiva dos povos.

Palavras chaves: professora rural, Historia de vida, condições sócio-econômicas, formação, desigualdade. 


\section{INTRODUCCIÓN}

Analizar la labor de la maestra rural en Boyacá, desde su entorno, familiar, social y cultural, nos permite identificar las transformaciones generadas desde los gobiernos liberales existentes en su etapa de vida y cómo repercuten de forma directa en el contexto educacional de las y los maestras/os rurales, quienes quedan en situación de vulnerabilidad socio-educativa, entendida como: "la pérdida de valores, bajos niveles de ingreso, dificultad para acceder a la continuación de estudios universitarios, la falta de acceso a capacitaciones que fortalezcan su formación como educadoras, que impactan en unos espacios de poder local e imaginarios socio-culturales que ocasionan su invisibilización, discriminación y auto-discriminación, en los contextos socio-político-culturaleducativopatriarcales" ${ }^{3}$.

Establecer las principales necesidades e intereses que en esos momentos presentan las maestras rurales del "ayer" y del hoy" permite conocer los factores que favorecen y dificultan su liderazgo, así como su desempeño como educadoras y, conforme a ello, su impacto socio-comunitario para buscar resignificar su rol en el contexto rural a través de las historias de vida de cada una de ellas. A su vez, el análisis de su labor como docentes nos permitirá conocer el cambio de mentalidades y costumbres ${ }^{4}$ respecto a la educación de la mujer, inmersa a inicios del siglo XX en una sociedad patriarcal, y ver la labor educativa como aquella que traspasa las relaciones de enseñanza-aprendizaje que se originan dentro del aula de clase, para tener un impacto social en la formación de valores, que aporta a su comunidad.

El entorno histórico en el que se analiza la siguiente historia de vida de maestra rural corresponde a los años de inicio y jubilación del desempeño docente de la maestra; sin embargo, tomamos con referente socio-político el periodo de 1930 a 1957, periodo de grandes cambios estructurales que contribuyen a la consolidación de espacios para la mujer. Por ello, desde la tradición teórica e historiográfica con que cuenta la Historia de las mujeres en el momento presente y de una forma específica en Historia contemporánea, permite considerar que se encuentra en la actualidad en un proceso de complejización y de desarrollo cualitativo, que la resituarían en unas perspectivas metodológicas vinculadas a

3. Magdalena Velázquez Toro. “Condición Jurídica y social de la mujer: educación y ciencia luchas de la mujer vida diaria”, en: Nueva historia de Colombia, Tomo IV. Álvaro Tirado Mejía (ed.). Bogotá: Planeta, 1989. Véase Soto, La maestra rural en Colombia, 2012, p. 3.

4. Diana Soto Arango et al. Historia de Vida de dos Maestras de Escuela a mediados del siglo XX en Colombia. Amparo y Andrea. Liberal y Conservadora en contextos de la ruralidad educativa cundiboyacense. En: Diana Soto Arango; Jesús Paniagua; José Rubens Lima Jardilino y María Cristina Vera (eds.). Educadores Latinoamericanos y del Caribe del siglo XX al XXI. Tunja: Ed. Doce Calles, 2012, p. 336. 
las que podemos caracterizar, de una forma amplia, como "Historia social"; es decir, en unas perspectivas centradas ya no solamente en la demanda de "visibilidad" de las mujeres como sujetos históricos, sino, sobre todo, interesadas en la explicación y comprensión del "género", no sólo como un sistema de representaciones culturales, sino, también y muy especialmente, como un conjunto de prácticas, relaciones y experiencias sociales históricamente determinadas.

Así, si tuviésemos que caracterizar brevemente en qué momento historiográfico se encuentra la Historia de las mujeres referidas a la época contemporánea, habría que referirse a un nivel de reflexión crítica sobre cómo entender, investigar, teorizar y avanzar en el conocimiento histórico, en su Historia y en sus presupuestos teóricos y metodológicos, a partir de un sujeto histórico tan significativo como son las mujeres, o como son las relaciones entre mujeres y hombres: las relaciones de género; y a partir, a la vez, de las articulaciones e interrelaciones existentes entre representaciones culturales e identidades diferenciadas y prácticas sociales.

La maestra que hemos tomado como parte del estudio se caracteriza porque no pertenece a ninguna élite intelectual ni administrativa; tiene como punto de encuentro cómo asumió la función de educadora, desde los valores humanos, en medio de un conflictos sociales y de imaginarios políticos que se acentúan con mayor fuerza en las poblaciones y zonas rurales de Colombia. Para esta investigación, se plantea el siguiente problema: ¿Incide la filiación política e ideológica de las maestras, con su historia de vida, en el desarrollo de la práctica educativa e impacto social local y de cambio de mentalidades en el Departamento de Boyacá durante la primera mitad del siglo XX? ${ }^{5}$.

\section{POR QUÉ LA FORMACIÓN COMO MAESTRAS RURALES EN BOYACÁ: PRIMERA DÉCADA DEL SIGLO XX}

A comienzos del siglo XX, Colombia atravesó por una serie de transformaciones sociales, políticas, económicas y culturales: "la transición de un modelo tradicional de la estructura agraria a un modelo de sociedad que se vendría a denominar moderna con características tales como: creciente proceso de Urbanización, creciente Desarrollo Industrial, ampliación de contactos culturales" ${ }^{\prime 6}$, que no debilitaron la influencia de la Iglesia, sino, por el contrario, la fortalecieron,

5. Véase: Diana Soto Arango y Justo Cuño Bonito. (coord.). La maestra rural en Colombia y Guatemala. Siglos XX y XXI. Historias de vida e intervención educativa de la Universidad. Proyecto de investigación inter-institucional con la Universidad Pablo de Olavide de España y el Grupo de investigación Historia y Prospectiva de la Universidad Latinoamericana.

6. Sandra Patricia Santamaría Bautista. La familia tunjana 1930-1946. Hegemonía liberal. Tunja: Universidad Pedagógica y Tecnológica de Colombia, 2009, p. 38 (Tesis de Maestría en Historia). 
como sucedió en Boyacá ${ }^{7}$, donde el clero mantuvo su poder político-religioso y legitimó el apoyo al Partido Conservador, como también las costumbres y creencias patriarcales.

Para 1938, un 94\% de la población se ubica en la zona rural, lo que se reflejó en las tasas de analfabetismo (en edad escolar, desde los 7 años en adelante) de $48,2 \%$ para los hombres y $51,8 \%$ para las mujeres ${ }^{8}$. Esta situación preocupó a los gobiernos nacionales, quienes, a través de políticas educativas, buscaron crear escenarios de formación y capacitación para las maestras, creación de instituciones educativas e incentivos para que las y los estudiantes acudieran a la escuela; estos incentivos y políticas educativas los implementaron desde comienzos del siglo XX los Secretarios de educación del Departamento de Boyacá.

Una de las causas se debió a que a los niños los llevaban los hombres de la casa a trabajar en labores agrícolas y ganaderas, mientras la madre, en el hogar, reproducía los rasgos tradicionales, acordes a los preceptos de una sociedad cristiana, que se fortalecían en los mismos establecimientos educativos.

En el Decreto 276 de 1930, se establecía:

\begin{abstract}
Art. 1. Crease para el uso de los alumnos y del público, una biblioteca escolar en cada una de las escuelas urbanas primarias oficiales del Departamento, la cual estará a cargo directo del respectivo maestro o maestra y será inspeccionada por una junta denominada Junta Protectora de la Biblioteca Escolar, integrada por el inspector local de la Educación, el alcalde y el presidente del concejo y dos señoras distinguidas de la localidad, designadas por los tres primeros miembros.

Art. 2. Se procurará que en estas bibliotecas abunden los tratados y revistas sobre Historia Patria y de las Repúblicas de la América Española, geografía comercial de la República y el Departamento, campaña antialcoholismo, Industria Agrícola, Pecuaria y Fabril, dominantes en la respectiva región, metodología de las materias que constituyen el pensum de las Escuelas Primarias y literatura clásica americana y española. Todas las obras de las
\end{abstract}

7. Boyacá surge como Departamento de la República de Colombia a partir de la Constitución Política de 1886. Luego de 4 años, el gobierno nacional, con la Ley 68 del 20 de noviembre de 1890, le cedió el territorio de Vásquez (actualmente Puerto Boyacá) y, por el Decreto Ejecutivo 306 de 1911, varios municipios se le segregaron para constituir la Comisaría de Arauca; posteriormente, los municipios pertenecientes a la Orinoquía formaron la Intendencia de Casanare, territorio que se le anexó nuevamente en 1950; en el año 1973, se segregaron de nuevo estos municipios para conformar el territorio actual. Boyacá limita al norte con el Departamento de Santander, al noreste con la República de Venezuela y el Departamento de Norte de Santander, al este con Arauca y Casanare, al sur con Cundinamarca y al oeste con Antioquia. Su territorio ocupa una superficie de $23102 \mathrm{~km}^{2}$, un área similar a la de la isla de Cerdeña. Véase: Alcaldía mayor de Tunja. www.alcaldiamayordetunja.com. Consulta: 20 de noviembre de 2011. Para el periodo de estudio, el Departamento de Boyacá cuenta con una población de 737.368, en 1938; es decir, registra solo un aumento de 85347 habitantes, respecto al Censo de 1918, que arrojó 652.021 habitantes. Cuenta con 125 municipios y una extensión que abarca el Corregimiento de Casanare con 0 a 5 habitantes por Kilómetro cuadrado. Censo General de la República. 1938, p. 6.

8. Alcaldía mayor de Tunja, p. 156. 
bibliotecas deben distinguirse por su moralidad y por contener doctrinas que no son contrarias a la religión católica, apostólica y romana.

Parágrafo. Las bibliotecas de las escuelas de niñas, tendrán, además, tratados y revistas sobre horticultura y jardinería, culinaria y demás propias de la mujer"'?

Estos condicionamientos socio-culturales fortalecieron la imagen de mujer sumisa y tuvo que acudir a asignarse a profesiones acordes a su condición biológica ${ }^{10}$, como ser maestra, madre o monja; la primera tuvo bastante demanda por la población femenina y se sujetó a las condiciones económicas, ya que era una de las pocas profesiones que podían pagar o a las que admitían por medio de becas, seguida por la enfermería o la cultura física; a las últimas sólo lograron acceder por medio del Decreto 1972, expedido en el año de $1933^{11}$. Las primeras becas que concede el gobernador del Departamento salen para 1936 y 1940.

\section{Decreto 178 de 1940}

(Marzo 28)

Por el cual se adjudican 10 becas en el curso de enfermería anexo a la Escuela Normal Rural.

El gobernador del Departamento, en uso de sus atribuciones legales y en cumplimiento del artículo $9^{\circ}$ de la Ordenanza $\mathrm{N}^{\circ} 11$ de 1939

\section{DECRETA:}

Artículo $1^{\circ}$. Las diez becas creadas por la Ordenanza 11 de 1939, previa a las condiciones requeridas para el caso, adjudicase a las siguientes señoritas:

1. Matilde Álvarez

2. Lilia Barrera

3. Beatriz Estrada

4. Etelvina González

5. Alicia Hernández

6. Constanza Quiñones

7. Elvia Rodríguez

9. Dirección de Educación Pública. Decreto número 276 de 1930, Periódico el Boyacense, Tunja, 23 de junio de 1930. (Transcripción del Decreto).

10. Para la época de estudio, las únicas profesiones bien vistas por la población colombiana, sobre todo la boyacense de costumbres conservadoras, era el de maestra, monja o madre, ya que con ellas preservaban los buenos valores y el cuidado de los demás.

11. Esto se logró luego de una constante movilización y organización de las mujeres para que les reconocieran sus derechos civiles y culturales en el año de 1930, con el IV Congreso Internacional Feminista, que contó con el apoyo del gobierno de Enrique Olaya Herrera, organizado por mujeres, donde participaron delegaciones nacionales e internacionales. Por Boyacá, participaron Ofelia Uribe y Luisa Ruiz de Amórtegui. Entre los temas que se debatieron estuvieron: Práctica y enseñanza de la Educación Física y deportes de la mujer, la mujer y la Universidad, mujer y participación política, capacidad civil de las mujeres. Gracias a estos procesos, se produjo la Ley 28 de 1932, que le dio la plena capacidad civil a la mujer y, por lo tanto, la habilitó en materia laboral para contratar; los Decretos 1874 de 1932 y 227 de 1933 reglamentaron el ingreso de la mujer a la Universidad. 
8. María Inés Barreto
9. Isabel Tovar
10. Inés Cárdenas

Artículo $2^{\circ}$. Desde el $1^{\circ}$ de los corrientes, las citadas alumnas tendrán un sueldo mensual de \$30-00 cada una, suma que se tomara del artículo 104 del Presupuesto vigente.

Comuníquese y cúmplase.

Dado en Tunja, a 28 de Marzo de 1940.

ANTONIO CÓRDOBA

Director de Educación Pública ${ }^{\mathbf{1 2}}$.

De cualquier modo, muchas mujeres continuaron asistiendo a las Escuelas Normales y Escuela de Artes y Oficios. Sólo para 1957, existía en Boyacá un total de tres Normales Superiores Nacionales: una para hombres y dos para mujeres, con un total de 799 alumnos y alumnas matriculadas ${ }^{13}$; asimismo, se encuentran funcionando dos establecimientos privados para mujeres. Para 1951, con un total de 944 personas que accedieron a estudios universitarios, de los cuales: 817 eran hombres y 127 mujeres ${ }^{14}$. En el caso de los establecimientos para normalistas rurales, el Departamento tenía seis instituciones, de las cuales dos eran nacionales y cuatro departamentales ${ }^{15}$.

Las Normales Rurales forman a las generaciones de maestras de la primera mitad del siglo XX en Boyacá, debido a que el $50 \%$ de la población es rural; además de la facilidad de acceso, los bajos costos permitieron que las mujeres se inclinaran por esta profesión, ya que a los hombres los admitían en otros oficios o profesiones. Esta situación determinó la dinámica de la educación media en Boyacá y la formación de maestras en las escuelas rurales. Para 1957, de un total de 1057 maestros oficiales (31 hombres y 1026 mujeres ${ }^{16}$ ), sólo 18 eran Normalistas Superiores, 33 Normalistas Rurales, 1 con Bachillerato, 17 con otro tipo de grado y $988 \sin$ grado ${ }^{17}$, lo que mostraba la poca preparación

12. Dirección de Educación Pública. Decreto 178 de 1940, Periódico el Boyacense, Tunja, 28 de Marzo de 1940: 98. (Transcripción tomada del periódico).

13. De este total, 349 eran hombres y 450 mujeres. De 898 estudiantes que presentaron el examen para optar el título de normalistas, sólo 143 hombres y 335 mujeres aprobaron. Véase: Anuario General de estadística, Normalista Superior (1957): 230,231

14. Censo de la Población de 1951, Grado Educacional de la Población por Municipios (1951): 235.

15. Anuario General de la Contraloría, Estadísticas Culturales (1957): 231.

16. Produjo una gran cantidad de demanda de esta profesión por parte de la mujer, por ser una prolongación de los condicionamientos sociales acordes a la época.

17. Los sueldos oscilaban de 151 a 300 pesos mensuales. Para el caso mencionado anteriormente, sólo 183 maestros tenían un sueldo de 101 a 150 pesos; 754 ganaban de 151 a 200 pesos; 50 ganaban de 201 a 250 pesos; 34 maestros ganaban de 251 a 300 pesos y 36 maestros más de 300 pesos. Estos sueldos los determinaba la cercanía a las capitales o ciudades. Estas son cifras tomadas del Anuario de Estadística, 1957: 163. 
y formación pedagógica, ya que se tenía contemplado que con el solo hecho de saber escribir, leer, sumar, restar y multiplicar podían ejercer como docentes en las zonas rurales y estos últimos terminaban en sitios totalmente aislados, que no contaban con presencia del Estado y sus habitantes establecieron sus propias leyes, acordes a la tendencia política y atendiendo a los mandatos del clero, que defendía la preservación de los valores cristianos y tradicionales para formar hombres y mujeres de bien y, desde el inicio de los gobiernos liberales, lanzaron imperiosos ataques a las reformas educativas que se habían gestado para fomento de las condiciones de igualdad entre sexos, pues las catalogaban de indecentes e inmorales.

Las Escuelas Normales rurales para mujeres las creó la Ley 12 del 17 de Diciembre de 1934 y se constituyeron en uno de los instrumentos privilegiados de los gobiernos liberales para implementar sus políticas de asistencia social a la población campesina ${ }^{\mathbf{1 8}}$; tenían como finalidad específica preparar a las maestras para educación rural primaria. Las instituciones se abrían a las jóvenes que hubieran terminado la primaria y que se prepararían, en dos años de internado, como docentes rurales; la formación incluía, de una parte, los conocimientos elementales y, de otra parte, los trabajos manuales y agrícolas ${ }^{\mathbf{1 9}}$.

Este oficio tampoco era mucho mejor visto que el de las costuras o criadas y se consideraba que la Escuela Rural estaba por debajo de la Escuela Urbana y, por lo tanto, eran maestras bastas. Sólo tenían a su alcance ciertos tipos de lectura: Vidas de Santos, libros de cocina y más vidas de santos. La Iglesia católica definía la enseñanza de las mujeres, a las que se veía como una llama que incitaba al pecado ${ }^{20}$.

Para las mujeres, ser maestra era casi la última alternativa. El magisterio aceptado como una prolongación del destino femenino maternal fue una de las pocas profesiones que se les permitía. La vida de las docentes no era fácil: después de terminar sus estudios, generalmente debían aceptar plazas en pueblos pequeños y lejanos; sus salarios eran exiguos y su condición de mujeres independientes, con nivel cultural y muchas de ellas con inquietudes intelectuales, las convertía en blanco de murmuraciones y objeto de control clerical ${ }^{21}$. Por ello, las maestras

18. Por el contrario, con la llegada de los gobiernos conservadores, para 1947 se crearon las Escuelas campesinas a través del Decreto 1760 de 1955, con las cuales se buscó contribuir al hogar y a que la mayor parte la dedicaran a la práctica de actividades domésticas, agrícolas. Según el Artículo 1. Parágrafo. Las alumnas de las Escuelas-Hogar para campesinas pueden ser internas, semiinternas o externas, becadas por la nación, el Departamento, el municipio, la parroquia, o entidades semioficiales y privadas.

19. Nidia Triana. Escuelas Normal Rural, Agropecuaria, y de campesinas en Colombia: 1934-1957. En: Revista Historia de la Educación Colombiana. Vol. 13, º13. (2010), p. 203.

20. Entrevista a Ofelia Uribe, en: María Cristina Laverde Toscano y Luz Helena Sánchez Gómez. Voces insurgentes. Bogotá, Universidad Central, 1986, p. 32.

21. Catalina Triana. Imágenes femeninas de Medellín a principios del siglo XX. En: Javier Guerrero (ed.). Cultura y mentalidades en la Historia de Colombia. Tunja, UPTC, 1995. 
buscaron preservar los valores, dedicar su tiempo a actividades bien vistas por la comunidad, el clero o el alcalde con el fin de no perder su única fuente de trabajo, mal pagada, ya que en muchas ocasiones pasaron meses sin pago, dependían de los mercados y presentes que les enviaban los padres de familia, al agradecer algún favor o como forma de reconocimiento por su labor.

Unido a lo anterior, la diferencia salarial que tenían las mujeres frente a los hombres, más aun si eran maestras en las zonas rurales, con dificultades de desplazamiento para llegar a su lugar de trabajo, sometidas a la violencia bipartidista que las alejaba de los lugares donde ejercieron por ser de otro partido opuesto a la población, falta de materiales (libros, cuadernos, tizas), la escasa preparación de las maestras, sus bajos recursos económicos y la carencia de políticas que las capacitaran en lugares alejados a los centros periféricos, no fueron obstáculos para ejercer con valor y entrega su labor como formadoras.

El gobierno buscó la creación de programas que permitieran establecer la igualdad entre la educación rural y urbana, pero la primera continuó con las mismas deficiencias:

A pesar de los esfuerzos por intensificar la cobertura de la educación primaria oficial, la franja de la población que no asistía a la escuela era muy amplia; según el Censo de 1938 la población en edad escolar alcanzaba la cifra de 1.760 .083 niños, de los cuales sólo asistía a la escuela el 33\%; para 1944, la población en edad escolar llegaba a 2.023.034 y el porcentaje de quienes asistían a la escuela al 33,5\%. A la dificultad de dar mayor cobertura educativa debido a la escasez presupuestal se le unió el aumento creciente registrado por la población en el transcurso del período, la cual experimentó cambios importantes (2,4\% por año en el período 1918-1938 y $2,6 \%$ entre 1938 y 1951$)^{22}$.

En medio de todos estos cambios socio-políticos, educativos y económicos, crecieron y formaron nuevas generaciones de maestras y maestros, que tuvieron la labor de ejercer en zonas aisladas.

\section{NIÑEZ Y FORMACIÓN COMO MAESTRA RURAL}

Flor de Orozco ${ }^{23}$ nació en el municipio de Arcabuco ${ }^{24}$, el 16 de noviembre de 1931, en una familia de origen conservador y tradicionalmente católica; su padre fue José de los Ángeles Niño Carreño y su madre María Antonia Franco, ambos

22. Martha Cecilia Herrera. Historia de la Educación en Colombia: La república Liberal y la modernización de la educación 1930-1949, http://www.pedagogica.edu.co/storage/rce/articulos/rce26_06ensa.pdf [Consulta 28/11/2012]

23. Entrevista a Claudia Orozco, Tunja, 4 de mayo de 2012.

24. Fundada el 22 de Octubre de 1856 como aldea y elevada al rango de distrito a partir del Decreto 28 de 1866, http://es.wikipedia.org/wiki/Arcabuco [Consulta: 06/11/2012]. 
dedicados a actividades agrícolas; de estrato medio y con buenas relaciones políticas, decidieron que la escuela primaria la debía cursar en el Colegio del Rosario, en Villa de Leiva. La madre ${ }^{25}$ tenía claro que su hija debía estudiar en la Escuela Bolivariana ${ }^{26}$, donde ingresó en el año 1945. En primero de bachillerato, las clases cotidianas las vieron en la mañana y en la tarde talleres de sastrería y modistería, tapicería, encuadernación, pintura, mimbre, tejido, pero en ninguno encontró satisfacción.

En el mes de mayo de 1945, se presentó a la convocatoria de Becas Nacionales, que aprobó, para iniciar, en Villa de Leiva ${ }^{27}$ como Normalista, en la institución Antonio Nariño ${ }^{28}$, a donde ingresó en calidad de interna ${ }^{29}$ el 18 de Junio de 1945. Fueron un total de $50^{30}$ niñas provenientes de varias regiones de Boyacá, los Santanderes y Cundinamarca, todas entre los 14 y 15 años $^{31}$.

La formación duró tres años, en los cuales las maestras profundizaron en materias como Psicología, Pedagogía y Metodología. La preparación como Normalistas Rurales era intensa; se iniciaba con una revisión de la Historia de las

25. Mi abuela tenía claro que quería que sus hijas estudiaran ya que solo se pensaba en darle estudio al hombre. Entrevista a Claudia Orozco. Tunja, 4 de mayo de 2012.

26. Funcionó en la Plaza de Bolívar, contigua al Edificio Nacional, demolido en el año de 1970, donde actualmente funciona la Dirección de Impuestos y Aduanas Nacionales (DIAN).

27. El domingo 12 de agosto de 1945 fue inaugurada solemnemente en la histórica Villa de Leiva la Escuela Normal Rural para señoritas por el gobernador Doctor Héctor Moreno Díaz, el secretario del Ministerio de Educación Nacional, señor Gustavo Uribe, el director de Normales del mismo Ministerio, Doctor Rafael Humberto Bernal, el director de Educación, doctor Ernesto Meléndez Sandoval, el ex gobernador de Boyacá y actual representante al Congreso, doctor Rafael Vargas Páez. Véase: Fondo Pedagógico No. 0118. Reseña y Discursos Pronunciados en el acto de inauguración de la Escuela Normal Rural. (Tunja: Imprenta Departamental, 1945), 3.

28. Anteriormente se conoció con el nombre de Convento de San Agustín, en el que vivió la comunidad agustina hasta poco después de 1821. Duró 40 años vacío hasta que en 1877 lo tomaron en arriendo las señoritas Emilia Buitrago y las hermanas Rosa y Virginia Umaña, quienes fundaron el Colegio de Nuestra Señora de Lourdes. En 1880, el dominico Fray Saturdino Gutiérrez fundó la Comunidad de las Terciarias Dominicanas. En 1944, las dominicas terciarias, obligadas por el gobierno Departamental, dejan el viejo Convento de San Agustín, que se adopta para la Escuela Normal Femenina "Antonio Nariño" y posteriormente lo restaura Monumentos Nacionales, http://villaleyvanos.com/autres/informacion/ historia/san_agustin/index.htm [Consulta 07 de noviembre de 2012. Hora: 09:09 p.m.]

29. En la institución "Antonio Nariño", del municipio de Villa de Leyva, recibió clases de la señorita Flor Ángela Hernández Santofimio, natural del Tolima, quien le explicó que ser Normalista Rural era prepararse para ser maestra rural. Tomado del escrito de la Maestra Flor de Orozco.

30. El curso de este año se abrió con cincuenta alumnas solamente, que se seleccionaron entre el magisterio boyacense; lo dirige la conocida y competente directora tolimense señorita Flor Ángela Hernández Santofimio, ampliamente conocida en todos los círculos educativos y a quien acompañan profesoras boyacenses destacadas. El local tiene capacidad para ciento cincuenta alumnas y tan pronto como se terminen los últimos detalles contemplados en el proyecto de reforma será uno de los mejores en su género, según aseveración del pedagogo colombiano doctor Agustín Nieto Caballero, quien quedó muy bien impresionado por esta obra del régimen liberal.

31. Recuerda que la violencia generada por los Partidos Políticos suscitó angustia e incertidumbre, lo que lo vivieron como internado. Existió una marcada diferencia entre los liberales y conservadores, que ocasionó rencillas entre ellas. Los papás marcaban las diferencias entre partidos cuando saludaban solo al amigo perteneciente a su corriente política. Véase escrito titulado: Por qué escogí ser normalista, de la maestra Flor de Orozco. 
Normales, profundizando en las maestras rurales de Normales Superiores de Señoritas ${ }^{32}$. Los maestros y maestras encargados de su formación, en su mayoría eran internos, entre los que se encontraba: el capellán, el médico o profesor de Anatomía, el agrónomo, el edufísico y el profesor de música. A las maestras rurales se las preparaba para que supieran enseñar; eran verdaderas consejeras; debían aprender sobre cuidado de salud y bebés en las materias de economía o cultura doméstica, lo que permitió que en los primeros años como docente gozara del amor, el respeto y el aprecio de la población.

Entre las materias importantes se encontraban: Matemáticas, Trigonometría, Lengua española, Ciencias Sociales (Historia Patria, Geografía de América, Geografía Universal), Cívica, Urbanidad e Historia Universal ${ }^{33}$. Se les enseñó la ortografía de José Manuel Marroquín, un catálogo que debía ser aprendido de memoria: "Con v se escriben van, alivio, mover, desvanecer, agravio, desvariar, maravilla, desvanecer, relieve, aseverar, acervo y varia".

En la clase de Matemáticas, siempre dio importancia al cálculo mental, con el empleo del juego de cabeza y cola. Además de ser obligatorias las tablas de multiplicar, en Trigonometría era indispensable el teorema de Pitágoras: "El cuadro construido sobre la hipotenusa de un triángulo rectángulo, es igual a la suma de los cuadrados de sus catetos". En la clase de cívica era necesario estudiar comportamiento de la sociedad, además de aprender de memoria la Constitución de 1986. Se graduó en el año de 1948; su diploma lo firmó el Ministro de Educación Dr. Fabio Lozano y Lozano y se lo entregó el gobernador del Departamento. Entre la misión de las futuras graduadas estaba la de librar una batalla desde el magisterio:

Para recorrer los campos, de la sierra al llano, llevando la luz de su saber para iluminar la inteligencia de los niños campesinos y con el buril de su apostólica tarea perfilar la fisonomía intelectual de un pueblo sumiso y laborioso que espera la redención de su inteligencia cautiva.

Los tropiezos y las inclemencias del medio serán obstáculo cotidiano a vuestra tarea, pero el deber será a cada paso el estandarte de vuestra jornada y no cejaréis en vuestro noble empeño ni os daréis por vencidas jamás porque vuestra profesión a través de su historia ha sido de constante sacrificio; no abandonaréis vuestros puestos y la aurora del mañana con una generación fresca y dispuesta a cantar para vosotras el fruto de vuestro trabajo en una plegaria a vuestra obra que os hará grandes y dignas de admiración y gratitud de toda una nación.

32. Funcionó donde queda hoy el Hotel Hunza y luego se trasladó a donde funciona actualmente la Escuela Normal Femenina "Leonor Álvarez Pinzón".

33. Esta materia, junto con Metodología y Psicología, son memorísticas. 
Ojalá vuestro trabajo sea fecundo y que cada día de vuestras labores sea una piedra más en el cimiento sobre el cual se empine enhiesto el mástil de nuestra cultura para que flote tranquila en él la bandera de la patria colombiana $^{34}$.

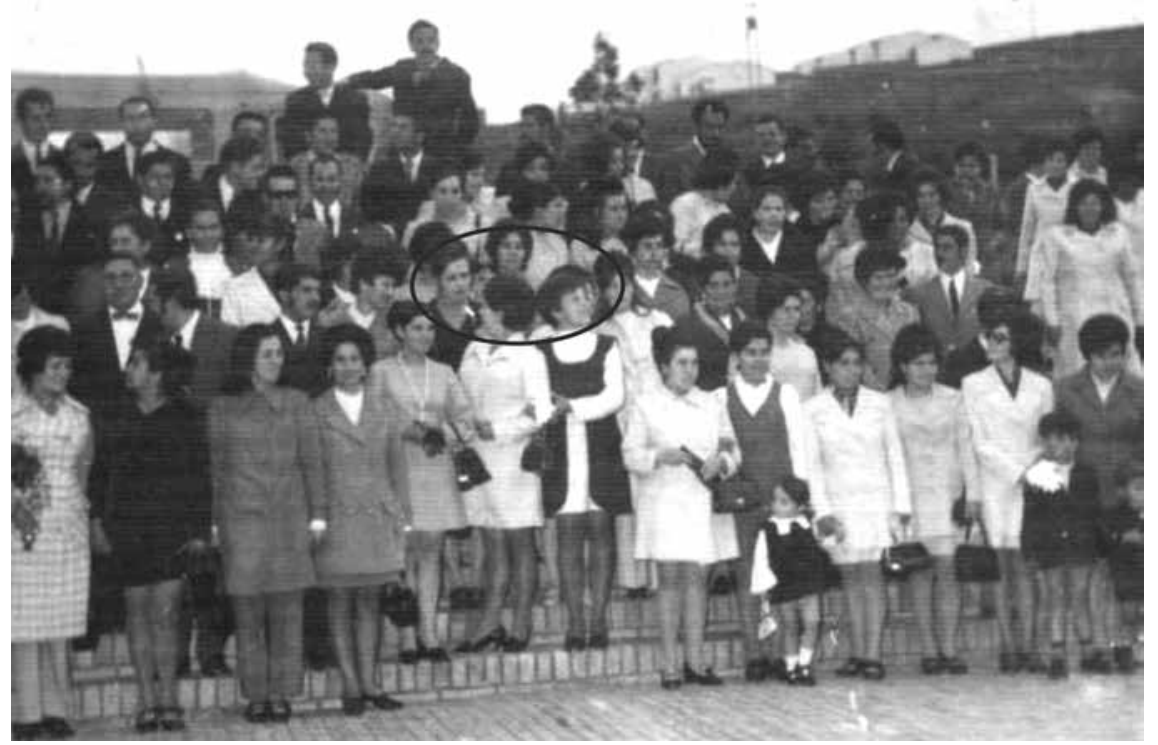

Foto tomada el día de la Graduación como Normalista Rural, $1948^{35}$.

\section{EL EJERCICIO DOCENTE: UNA MIRADA DESDE SU PROTAGONISTA}

Flor inició su labor como docente en la vereda de Sogamoso, donde ejerció solo dos años ${ }^{36}$, y la trasladaron a Tuta, a la vereda de Pedregal, donde trabajó durante 10 años; luego, ejerció en Santa Sofía, donde compartió labores con su hermana Blanca Niño Forero, pero por problemas en la zona de violencia bipartidista, solicitó su traslado para el Municipio de Arcabuco, donde cada ocho días se reunía con sus amigos y amigas en fiestas y tertulias, para compartir poesías, cantos, que todos componían. Así conoció al señor José Orozco ${ }^{37}$, con quien contrajo matrimonio ${ }^{38}$.

34. Fondo Pedagógico, 12.

35. Esta foto corresponde al archivo personal de la maestra Claudia Orozco, quien ha suministrado información sobre su madre: Flor de Orozco.

36. Estuvo allí poco tiempo debido a que su padre se enteró de que había un muchacho del Partido Liberal interesado en ella, por lo que él decidió venir hasta la ciudad de Tunja, a la Secretaría de Educación, donde solicitó su traslado; la sacaron, acompañada de la Policía, para evitar que la población los linchara.

37. Este hombre fue el Recaudador de rentas encargado de pagar a los maestros y maestras rurales de la época. Entrevista a Claudia Orozco. Tunja, 4 de mayo de 2012.

38. De esta relación nacieron sus cinco hijos, quienes actualmente se desempeñan como docentes en Bogotá, Sutamarchán y Tunja. 
Recuerda, con mucha tristeza, que sus primeros años como docente fueron demasiado duros, por la violencia generalizada en todo el país (incitada por los líderes de cada partido a nivel nacional, regional y local). Siempre que llegaba a una Escuela, les tocaba hospedarse en un salón pequeño y acoplarlo a sus necesidades, o tenían que acudir a solicitar la ayuda al párroco del pueblo, quien las hospedaba en la Casa Cural. Muchas de las maestras rurales solteras tenían que trabajar hasta los domingos, para llevar a los niños a la misa de 10 de la mañana, los que tenían que comportarse bien pues de ello dependía su estadía ${ }^{39}$.

Entre los obstáculos encontrados en el ejercicio docente, señala que muchos padres concibieron la escuela como forma de castigo para sus hijos cuando no cumplían con sus actividades en el campo, por lo que llegó a tener muchos inconvenientes con los políticos de turno.

Se caracterizó siempre por su liderazgo y colaboración en la comunidad. Los sábados salía con los niños, las niñas, las madres y padres de familia a realizar labores de embellecimiento en el colegio; gestionó, ante los entes gubernamentales, para mejorar los servicios básicos. Le encantó incentivar las huertas escolares en las instituciones y a ellas les dedicó trabajo con sus estudiantes, pues los productos obtenidos se comercializaban para satisfacer las necesidades de la comunidad, de la institución y sus propios gastos, ya que los pagos se demoraban y, al comienzo, varios sueldos los recibió en cajas de aguardiente ${ }^{\mathbf{4 0}}$, que vendía en las tiendas y con los padres de familia.

Gracias a su carisma y su capacidad de organización, decidió formar el sindicato, que le permitió crear un espacio en el que todas y todos pudieran trabajar en la exigencia de mejores condiciones laborales para los maestros. Hizo parte de varias Coordinaciones Nacionales y promovió los paros como rechazo a los mecanismos de presión, de violencia y la politiquería existente en el nombramiento de personal en las Secretarías de educación local, regional y nacional. Asimismo, evoca el día en que vino un sacerdote a brindarles una capacitación sobre cooperativismo, por lo que tenían como tarea dejar en la ciudad de Tunja fundada una Cooperativa, que surgió de la convicción de 17 maestros y tomó el nombre de Coeducadores.

39. En sus tiempos libres, la vigilaban el párroco y el alcalde, quienes calificaban su modo de vestir y comportarse, que debían ser acordes con los preceptos de la Iglesia Católica.

40. Según la Ordenanza 2 de 1925, expedida el 23 de marzo, se destinó parte de la renta de bebidas fermentadas a la Instrucción Pública; en el Artículo $1^{\circ}$ se ordena: Desde la promulgación de la presente Ordenanza, el treinta por ciento (30 por 100) de la parte que corresponde al Departamento en el producto líquido de la renta por impuesto sobre bebidas fermentadas, se destinará para atender a las necesidades más urgentes de la Instrucción Primaria, de acuerdo a lo que sobre la materia apruebe la Asamblea Departamental. 
Estos espacios, promovidos y consolidados a través de los procesos sociales, le permitieron construir una nueva cosmovisión de mujer, que rompe con los parámetros tradicionales enseñados en el hogar y contribuyó al despertar de los maestros para lograr su reconocimiento en una sociedad de inequidades ${ }^{\mathbf{4 1}}$.

\section{QUÉ, CÓMO Y CUÁNDO ENSEÑAR}

La metodología empleada por la maestra era la de crear contextos que les permitieran familiarizar y comprender a través del dibujo, trazos específicos retroalimentados dentro y fuera del aula de clase, para aprovechar la creatividad y las habilidades de los niños, los que fomentaron la escritura y la lectura a través de las zarzuelas, la poesía, las coplas elaboradas por ellos mismos.

Le gustaba sacar a pasear a sus estudiantes al campo, donde tenían como tarea recopilar las leyendas y mitos que les permitieran reconocer su riqueza cultural y ancestral para reconocer y aceptar al otro con sus habilidades, destrezas, similitudes y diferencias. Le encantaba ejercitar la memoria con salves elaboradas por ellos mismos, así como la que repetía diariamente antes de iniciar sus labores:

Cuando de mi Patrona subo a la ermita, Se me hace cuesta abajo la cuesta arriba y, cuando bajo, se me hace Cuesta arriba la cuesta abajo.

Cuando de mi Patrona

Llego a la ermita, desde su altar me lanza una sonrisa

$\mathrm{Y}$, al saludarla, me postro de rodillas

Para implorarle.

Abre, entonces, su manto, mi Virgencita,

$\mathrm{Y}$ un perfume del alma tiende la brisa

Dulce ternura, dulce ternura,

Riega sobre mis penas la Virgen pura ${ }^{42}$.

Siempre, antes de iniciar clase, llamaba a lista y hacía preguntas sobre las tareas dejadas y lo visto en el día anterior. Se preocupó por ejercitar la memoria para "grabar" conocimientos y una de las estrategias más utilizadas, durante su trayectoria como docente de primaria, fue la implementación del juego para la

41. Cuando la gente tiene presión y los sistemas de poder ejercen un control, cuestiona sus acciones y capacidades, pero la formación integral y superior es capaz de superar obstáculos y seguir haciendo lo que se tiene que hacer aun a costa de perder el pago, arriesgar su puesto, perder amistades, influencias, esto hace que cada día las convicciones de lucha marquen el sentido del argumento, ya que los poderes son pasajeros, las convicciones y el sentir de las injusticias no.

42. Esta salve se la enseñó su maestra cuando inició como Normalista en Villa de Leiva. 
enseñanza de áreas como las matemáticas ${ }^{43}$, complementado con los ejercicios, con inclusión del medio que los rodea.

En sus escritos, señaló que, antes de enseñar las operaciones básicas, como suma, resta, multiplicación y división, enseñó primero la noción de cantidad y su definición, la que repetían todos los días los niños: "Cantidad es todo cuanto se puede aumentar, disminuir, medir o contar, como el dinero, las ovejas de un corral".

Buscó que la niña y el niño pasaran de lo simple a lo compuesto, de lo concreto a lo abstracto, a través de ejercicios de memoria, que se estimulaban diariamente en las dos primeras horas de clase; había niños que aprendían muy rápido y colaboraban al enseñarles a los demás, ya que se tenía en un mismo salón de clase niños de diferentes edades y grados.

Asimismo, por carencia de materiales, para la enseñanza de las Ciencias Sociales, buscó que las niñas y niños llevaran una tabla grande de madera y aserrín para los mapas locales, regionales y nacionales, con aplicación de tiza en su interior. Luego venía el descanso y continuaba con las otras materias, hasta la hora de salida de los niños, cuando muchos se desplazaban a pie en trayectos de más de una hora para regresar a sus casas, con tareas que desarrollar para el día siguiente.

\section{CONCLUSIÓN}

Pese a los cambios que generaron los gobiernos liberales respecto a la situación de la mujer y su acceso a todos los ámbitos de la sociedad, las mujeres de clase media y baja sólo pudieron acceder a las Normales Rurales para mejorar sus condiciones de vida, mientras aquellas con recursos económicos lograron ingresar a la Universidad y a carreras que antes les eran ajenas por su condición de "mujer". En muchas ocasiones, se rebelaron ante las condiciones de subordinación y exclusión a las que las expuso el clero; lideraron procesos, dentro y fuera de las instituciones, para pedir recursos y mejores condiciones para los estudiantes, el maestro y la población.

La formación de la maestra rural del siglo XX tuvo que enfrentar la violencia bipartidista y las vicisitudes de la zona; como educadora, fue la consejera de estudiantes, padres y madres de familia, lo que dejaba ver su lado humano cada vez que brindaba una palabra de aliento y apoyo a quien lo necesitara.

43. Como se trabajaba en campo abierto tenía que comprar mucho material de juegos para que los niños aprendieran los temas, tanto de matemáticas, como Español y Sociales. 
Esta maestra, como muchas otras, encaró el miedo y el silencio que origina la violencia que mantiene este país, para pasar inadvertida y hacer más fácil su supervivencia, sin contar con los peligros que diariamente tuvo que enfrentar cuando se desplazaba a la institución en la que laboraba por el fuego cruzado que mantenían las familias, por sus odios bipartidistas. Como puede verse, la maestra, a través de su historia de vida, no sólo reconstruye las tradiciones culturales en las que la formaron como mujer que corresponde a una sociedad conservadora y patriarcal, sino, a su vez, muestra la capacidad de liderazgo y cooperación que traspasa las relaciones de enseñanza/aprendizaje que se mantienen en un salón de clase. Con este trabajo, se ha buscado visibilizar las necesidades, el contexto de vulnerabilidad y exclusión social a los que se someten y han estado sometidas diariamente las maestras rurales que han sido silenciadas y desconocidas como sujetos formadores e integradores que contribuyen a la construcción de sociedades más pacíficas y tolerantes, sin que una bala o varias horas de camino pusieran fin a sus sueños: el formar seres capaces de investigar y aportar a una nación. 


\section{REFERENCIAS BIBLIOGRÁFICAS}

\section{Fuentes}

Censo General de la República, de 1938.

Dirección de Educación Pública. Decreto 276 de 1930, Periódico el Boyacense, Tunja, 23 de junio de 1930.

Fondo Pedagógico No. 0118. Reseña y discursos pronunciados en el acto de inauguración de la Escuela Normal Rural. Tunja: Imprenta Departamental, 1945.

Ley 12 del 17 de diciembre de 1934.

Anuario General de la Contraloría, Estadísticas Culturales. Tunja, 1957.

Entrevista a Claudia Orozco; Tunja, 4 de mayo de 2012.

Dirección de Educación Pública. Decreto 178 de 1940, Periódico el Boyacense, Tunja, 28 de marzo de $1940: 98$.

Censo General de la Población 1957.

\section{Referencias}

Álvarez Gallego, Alejandro. Y la escuela se hizo necesaria. En busca del sentido actual de la escuela. Bogotá: Editorial Magisterio/Sociedad Colombiana de Pedagogía, 1995.

Cataño, Gonzalo. Educación y clase social en Colombia, http://www.pedagogica.edu.co/storege/rce/artículos/ 1-9pole.pdf.

Centro Interdisciplinario de Investigaciones sobre Desarrollo (CIDER). La nueva ruralidad. Bogotá: Universidad de los Andes, 2000. (Serie documentos conceptuales).

Entrevista a Ofelia Uribe, en: Laverde Toscano, María Cristina y Luz Helena Sánchez Gómez. Voces insurgentes. Bogotá, Universidad Central, 1986.

Herrera, Martha. Modernización y Escuela Nueva en Colombia. Bogotá: Universidad Pedagógica Nacional/ Plaza y Janés, 1999. (Serie Educación y Cultura).

Herrera, Martha Cecilia y Carlos Low. Los intelectuales y el despertar cultural del siglo. El caso de la Escuela Normal Superior, una historia reciente y olvidada. Bogotá: Universidad Pedagógica Nacional, 1994.

Jaramillo Uribe, Jaime. La educación durante los gobiernos liberales. 1930-1946, en: Nueva Historia de Colombia. Vol. IV. Álvaro Tirado Mejía (ed.). Bogotá: Editorial Planeta, 1989.

Reyes Cárdenas, Catalina. Imágenes femeninas de Medellín a principios del siglo XX, en: Guerrero Barón, Javier (ed.). Cultura y Mentalidades en la Historia de Colombia. Tunja: UPTC, 1995.

Soto Arango, Diana Elvira. La ruralidad en la cotidianidad escolar colombiana. Historia de vida de la maestra rural boyacense. 1948-1974. Revista Historia de la Educación Latinoamericana. No. 18. (2012).

Soto Arango, Diana. Historia de vida de dos maestras de escuela de mediados del siglo XX en Colombia. Amparo y Andrea. Liberal y Conservadora en contextos de la ruralidad educativa cundi-boyacense. En: Diana Soto Arango, Jesús Paniagua, José Rubens Lima Jardilino y María Cristina Vera de Flash. Educadores latinoamericanos y del Caribe del siglo XX y XXI. Tunja: Ediciones doce calles, 2011. 
Ramírez, María Teresa y Juana Patricia Téllez. La Educación Primaria y Secundaria en Colombia en el siglo XX. Bogotá: 2006, http://www.banrep.gov.co/docum/ftp/borra379.pdf (Consulta 01 de Marzo de 2013).

Triana, Alba Nidia. Escuelas Normal Rural, Agropecuaria y de campesinas en Colombia: 1934-1957. Revista Historia de la Educación Colombiana. Vol. 13, º13 (2010).

Velázquez Toro, Magdalena. Condición Jurídica y social de la mujer: educación y ciencia luchas de la mujer vida diaria. En: Nueva historia de Colombia, Tomo IV. Álvaro Tirado Mejía, Jorge Orlando Melo y Jesús Antonio Bejarano (eds.). Bogotá: Planeta, 1989.

Santamaría Bautista, Sandra Patricia. La familia tunjana 1930-1946. Hegemonía liberal. Tunja: Universidad Pedagógica y Tecnológica de Colombia, 2009 (Tesis de Maestría en Historia). 